\title{
Evaluation of Heat and Current Characteristics of Bypass Diodes for Fault Detection in Photovoltaic Module
}

\author{
Keiichi Okajima and Mizuki Hakura \\ Department of Risk Engineering, University of Tsukuba, Tsukuba 3058573, Japan
}

Received: November 30, 2016 / Accepted: December 07, 2016 / Published: March 31, 2017.

\begin{abstract}
In recent years, PV (photovoltaic) systems have been installed rapidly around the world. However, there is often a delay in the practical application of fault detection in PV systems. In this study, the temperature of BD (bypass diodes) mounted on PV modules was measured for simple and practical fault detection. The temperature of the BD of Module 31 was higher than other modules and a large current passed through one of the BDs. Measuring BD temperatures is easier than other conventional methods of fault detection. From the results of the rise in BD temperature under dark conditions, the increase in temperature increased linearly with increasing current flow. There is a proportional relationship between heat generated and the increasing temperature of the terminal box. The experimental results about surface temperature of the junction box in actual system operation suggested that the electric current through a BD in a terminal box can be known by measuring the surface temperature of the terminal box for PV module fault detection without a system shutdown. Moreover, we tried to evaluate temperature distribution of a terminal box using heat conduction equations. The evaluated results agreed well with the measured results.
\end{abstract}

Key words: PV system, bypass diode, fault detection, heat loss.

\section{Introduction}

Solutions to environmental problems such as the exhaustion of fossil fuels and GHG (greenhouse gas) emissions are required for sustainable development. Renewable energy resources are supposed to be one of the most efficient and effective solutions. Solar energy is produced by collecting sunlight, and is probably the most important form of renewable energy available today. In recent years, solar PV (photovoltaic) systems have been installed rapidly around the world. The installed total capacity of solar PV systems was estimated to be approximately $228 \mathrm{GW}$ at the end of 2015 [1]. In particular, China, Japan and the United States, have led this growth. A total of $33 \mathrm{GW}$ of PV systems were installed in these countries in 2014.

Corresponding author: Keiichi Okajima, associate professor, reseach fields: fault detection and PV system, fuel cell system.
However, there is often a delay in the practical application of fault detection in PV systems. In general, PV modules should have a service life of at least twenty years [2]. Unfortunately, it is difficult to observe a failure in PV modules because modules installed on roofs operate silently and are difficult to observe visually. This makes it difficult to identify meaningful performance drops. Therefore, it is important to develop smart diagnostic techniques for PV systems.

Many factors, such as mismatch effects and shadows, may cause at reduction in output power of PV modules. Hot spots can happen due to mismatch or in the presence of shadows on the PV module, often causing damage. BD (bypass diodes) are included in PV modules by manufactures in order to prevent hot spot formation, in partial shadowing conditions. There are previous studies about bypass diode for improved hot spot reliability of PV panels, such as construction 
of simulation models [3-5], measurements of $I-V$ characteristics [6-8], a proposal of a modified bypass circuit $[9,10]$. Thus, the configuration of BDs in PV modules has an important influence in the possibility of hot spot apparition and the reliability of the PV system.

In this study, we focused on increasing the temperature of BDs on a PV module to simulate simple failure detection. BDs allow currents to be distributed around shaded cells and also reduce voltage losses through the module [11, 12]. Thereby, BDs can run hot when the current is distributed around. We then evaluated the relationship between the increase in temperature at BDs and the current that was distributed around on the PV module that corresponded with a failure.

\section{Experimental PV Systems}

There are more than $200 \mathrm{PV}$ systems installed at the AIST (National Institute of Advanced Industrial Science and Technology) Tsukuba Central. The PV system located at district 7-3B, named 7-3B-2, was chosen as the object of this study. Fig. 1 shows an image of 7-3B-2. This system has been in operation for approximately five years, and does not have any history of repair or exchange.

Specifications for this system are shown in Table 1. The system has a total capacity of $4 \mathrm{~kW}$, and the PV array consists of 32 modules. The rated output power of each module is $126 \mathrm{~W}$. Fig. 2 shows a schematic diagram of the components in 7-3B-2. The PV array is divided into three sets of modules connected in series,

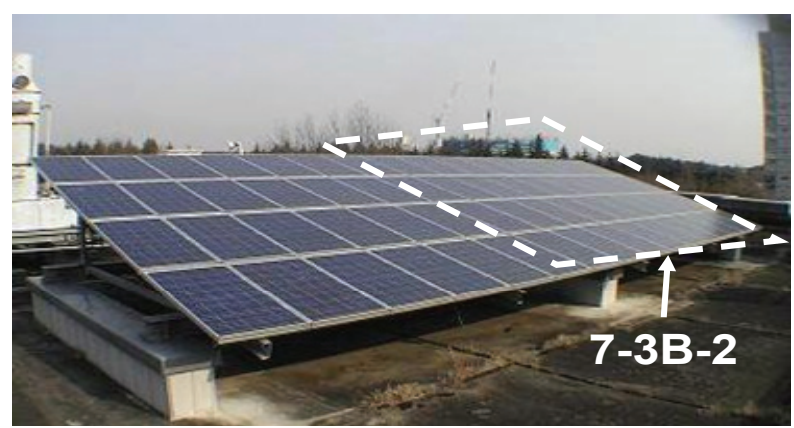

Fig. 1 Appearance of the PV system.
Table 1 Specifications of the PV system.

\begin{tabular}{ll}
\hline PV module & Polycrystalline Si \\
\hline$P_{\max }$ & $126 \mathrm{~W}$ \\
$V_{\mathrm{OC}}$ & $24.1 \mathrm{~V}$ \\
$I_{\mathrm{SC}}$ & $7.12 \mathrm{~A}$ \\
$V_{\mathrm{PM}}$ & $19.2 \mathrm{~V}$ \\
$I_{\mathrm{PM}}$ & $6.56 \mathrm{~A}$ \\
Number of BDs & 2 \\
\hline \multirow{2}{*}{$\mathrm{PV}$ array } & 10 series 1 parallel, \\
\hline Rated power output & 11 series 2 parallel \\
Orientation & $4.032 \mathrm{~kW}$ \\
Inclination & $24.2^{\circ}$ from the level \\
\hline
\end{tabular}
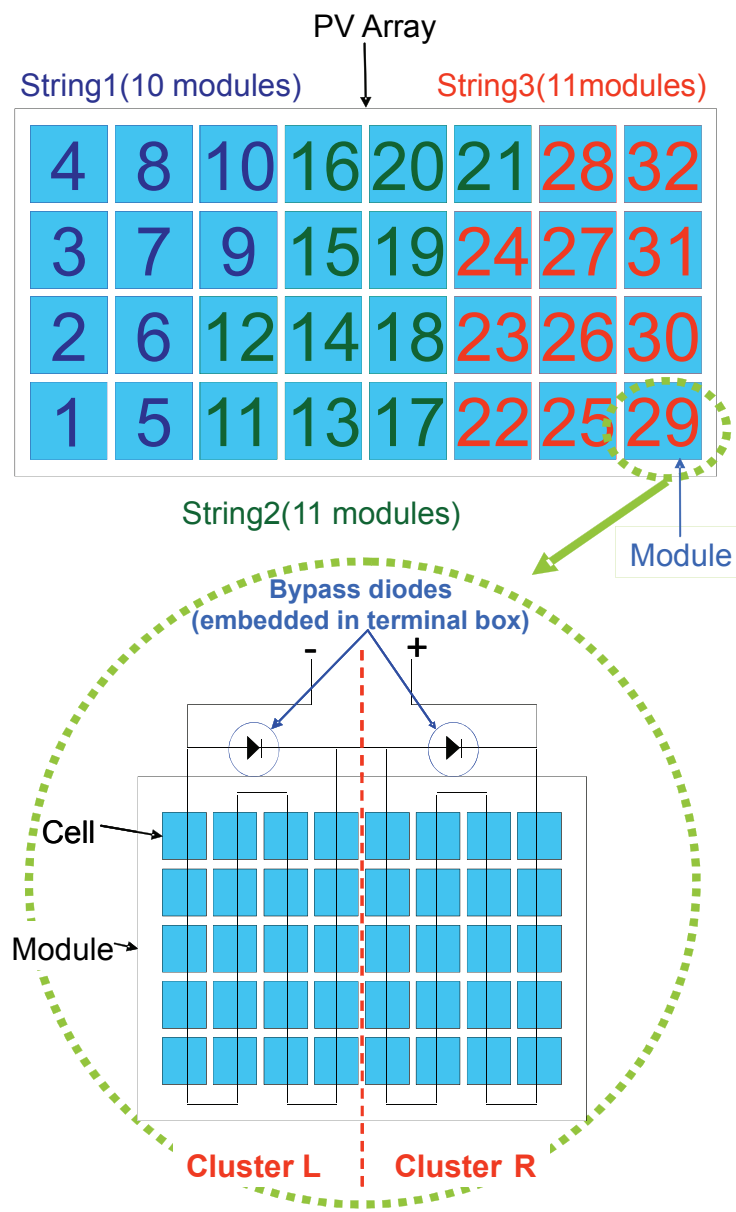

Fig. 2 Schematic diagram of strings, module clusters.

i.e., PV strings. String 1 has ten modules, while String 2 and String 3 both have eleven modules connected in series. Each PV module of the system has two BDs between each string of cells, namely, "a cluster". In other words, each module is composed of two clusters. 


\section{Conditions of the PV System}

\subsection{I-V Curves}

$I-V$ curves for each cell were measured using an $I-V$ tracer (EKO MP-170) as shown in Fig. 3. Open circuit voltage $\left(V_{\text {oc }}\right)$ of Module 31 dropped to $11.1 \mathrm{~V}$, corresponding to approximately one half of the rated $V_{\mathrm{oc}}$ of the normal module. It was supposed that one of the two clusters in Module 31 had some failure due to the drop in $V_{\text {oc }}$ by half.

\subsection{IR Images Observation}

Back side temperatures on each module of the PV system were then observed while in operation using an infrared camera (Thermo Delta, MobIR M4) mainly on terminal boxes. As a result, specific temperature distribution was observed on Module 31 as was detected by the $V_{\text {oc }}$ drop. Fig. 4 shows the IR images of Module 31.

It was found that a part of the terminal box ran hot as shown by the IR images. Therefore, it was thought that the $\mathrm{BD}$ in the terminal box ran hot. It was revealed that the temperature of Cluster $\mathrm{R}$ became uniformly higher than that of Cluster $\mathrm{L}$ as shown by the back side image of the module. It was supposed that the input energy from solar irradiation was converted to heat loss because the cells in Cluster $\mathrm{R}$ were not generating electricity.

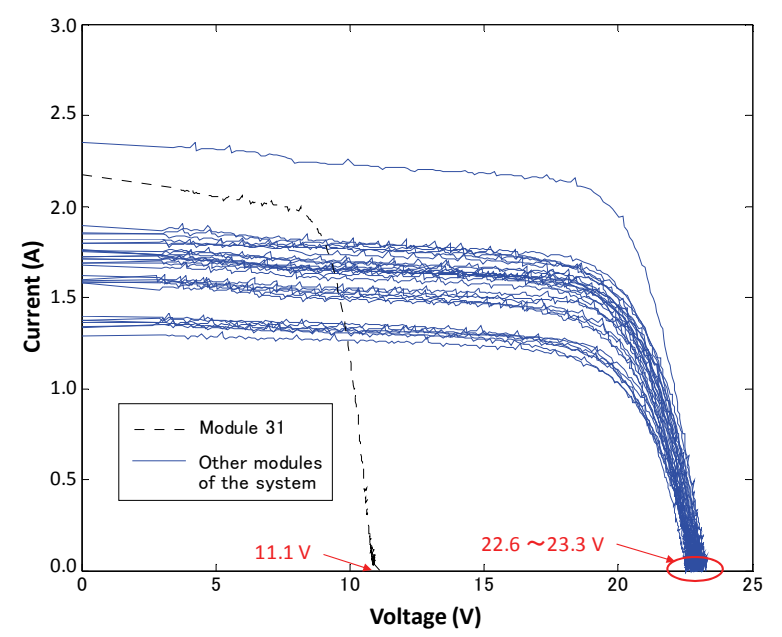

Fig. $3 I-V$ characteristic curve on each module of the system.



Fig. 4 IR images of Module 31.

\section{BD Temperature with Electric Load under Dark Conditions}

A rise in temperature was evaluated when an electric current flowed through a BD as a preparatory experiment. The module that normally generated electricity was connected to a DC power supply and a constant current was applied under dark conditions. Surface and internal temperatures of the terminal box were then measured using a data logger.

\subsection{Experimental Conditions}

Terminal box surface temperatures and internal temperatures (i.e., surface temperatures of the BDs inside the terminal box) were measured at currents with regular increments of $1 \mathrm{~A}$ using thermocouples and data loggers. For a more accurate measurement of the internal temperature, the terminal box faceplate was taken off, and the thermocouple was stuck on a metal plate facing inward using a silver paste with high thermal conductivity. Schematic photos are shown in Fig. 5. Then, the filler was put back for temperature measurements.
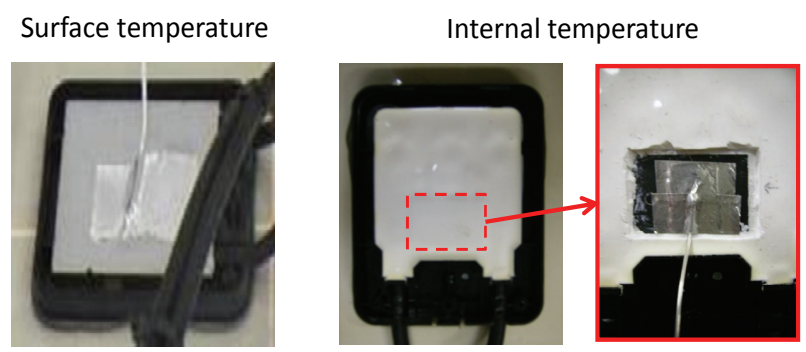

Fig. 5 Schematic photos for surface and internal temperatures measurement of the terminal box. 


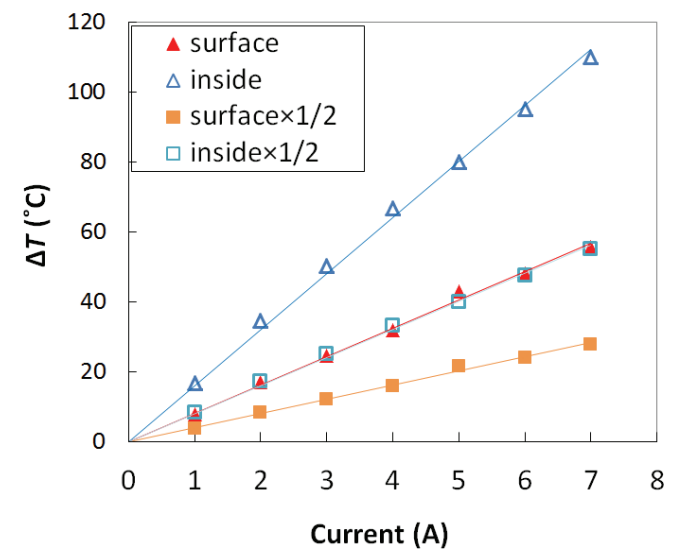

Fig. 6 Effects of load current on temperature of BD (dark).

\subsection{Effects of Load Current on the Temperature of the} $B D$

The correlation between current flow through the $\mathrm{BD}$ and the equilibrium conditions of the temperature on the terminal box is shown on Fig. 6. $\Delta T$ shows the increase in temperature for each experiment. From the results, $\Delta T$ increased linearly with increasing current flow. The temperature rose by more $50{ }^{\circ} \mathrm{C}$ at a current of $7 \mathrm{~A}$. This figure also shows that there is a proportional relationship between heat generated due to the energization of the $\mathrm{BD}$ and the increasing temperature of the terminal box.

\section{Surface Temperature Measurement of the Junction Box in Actual System Operation}

In order to detect a fault in Module 31 from the behavior of the obtained temperature data, we investigated the PV system. The schematic diagram of the experimental apparatus is shown in Fig. 7. The surface temperature of the junction box during system operation was measured with the surrounding temperature every $5 \mathrm{~min}$, using wireless thermo logger equipment. Furthermore, the current and the voltage of each string, and solar radiation were measured every second. The measurements were carried out for two days.

The results of String 3 including Module 31 are as follows. Figs. $8 \mathrm{a}$ and $8 \mathrm{~b}$ show the effects of string current on the temperature of the $\mathrm{BD}$ terminal boxes

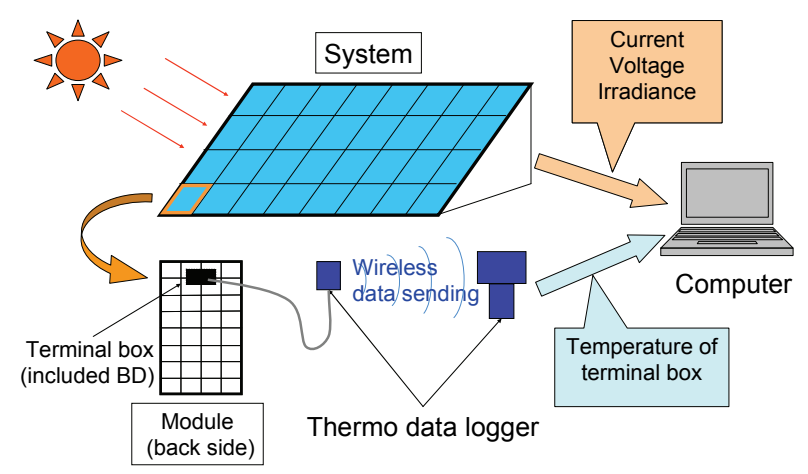

Fig. 7 Schematic diagram of the experimental apparatus for temperature measurement of the junction box in actual system operation.

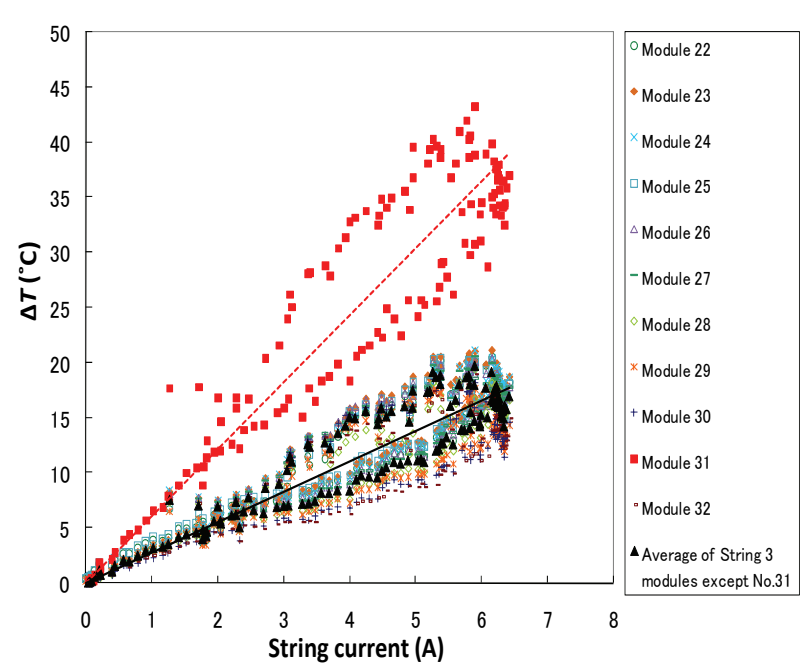

(a) Day 1

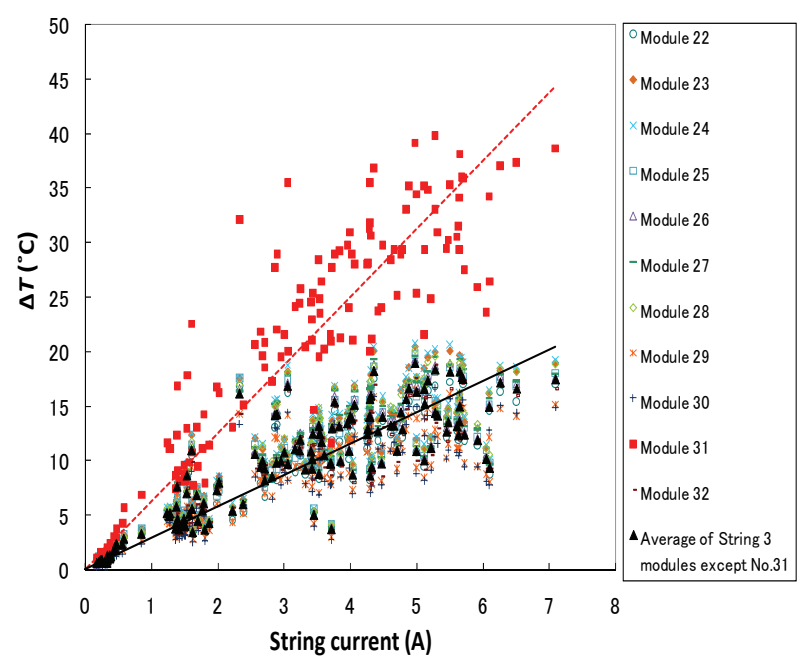

(b) Day 2

Fig. 8 Effects of string current on the temperature of the BD terminal boxes on (a) Day 1 and (b) Day 2; the straight line is an approximation of the average of the String 3 modules except Module 31. 
over two days. $\Delta T$ is the temperature increment of the terminal box surface from ambient temperature. The red dashed line shows the trend of Module 31 and black solid line is the approximation of average of String 3 modules except Module 31. In all modules, the terminal box surface temperature increased with an increase in the string current.

In general, the terminal box surface temperature is proportional to the electric current because the electric current increases with increasing irradiance on the solar PV panel, and the irradiance also heats the solar panels. However, Module 31 showed a large increase in temperature. The inclination of the trend of Module 31 on Day 1 was 6.09 , while that for the String 3 modules except Module 31 was 2.87. On the second day, the obtained results show similar tendencies. The calculated slopes were 6.23 and 2.87 for Module 31 and others, respectively. Thus, it was supposed that Module 31 was running hot, as heat generation occured by current loss through the BD in the module.

Then, the rise in temperature as a result of Joule heating with current through the BD was estimated by considering the rise in temperature owing to irradiance. Fig. 9 shows the effects of current on BD and terminal box temperature with the experimental results of the BD temperature under dark condition as shown in Fig. 6. $\Delta T$ for Module 31 is the difference between the

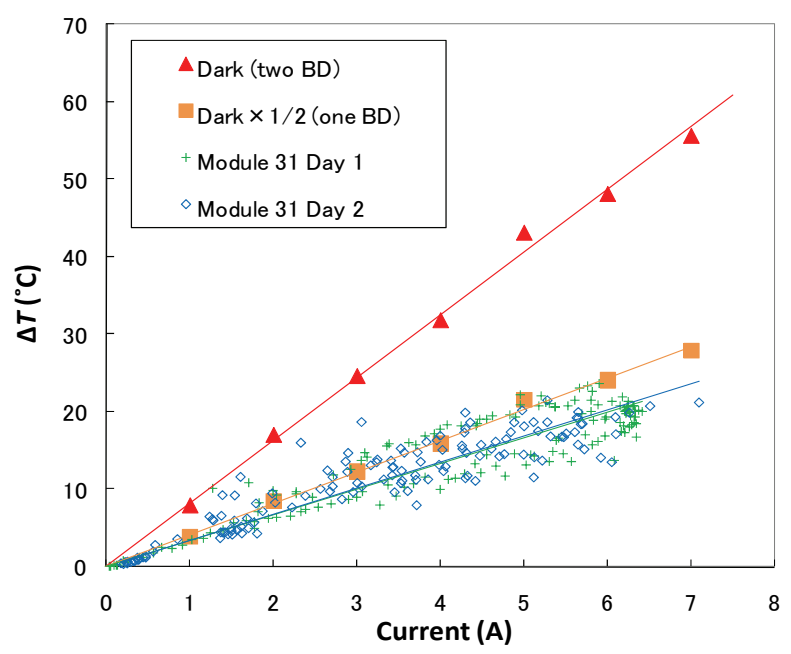

Fig. 9 Effects of current on BD and terminal box temperature. temperature of the module and the average temperature except Module 31.

The inclination of Module 31 is almost equal to the obtained results of a single BD under dark conditions, which indicates that an electric current always flows through one $\mathrm{BD}$, which shows that there is a failure on a cluster of Module 31. Thus, it was supposed that the electric current through a BD in a terminal box can be known by measuring the surface temperature of the terminal box for PV module fault detection.

\section{Simulation of Two-Dimensional Temperature Distribution}

In order to consider the relationship between the Joule heat caused by the current of the BD and the rise in temperature, we attempted to calculate the current flow through the BD from the surface temperature of the junction box. Fig. 10 shows the schematic diagram of the cross section of the junction box on a PV module that contains two BDs. The boundary of the module was set to be in contact with the junction box. The heat generated by the BDs, $W(\mathrm{~W})$, is derived using Joule's law:

$$
W=I^{2} R
$$

$I(\mathrm{~A})$ and $R(\Omega)$ is the current and resistance of the $\mathrm{BD}$, respectively. The temperature on the surface of the BD box in the junction box, $T_{1}$, was estimated using the temperature at the surface of the junction box, $T_{2}$, and $W$ was determined using a two-dimensional heat transfer equation:

$$
\frac{\partial}{\partial x}\left(k \frac{\partial T}{\partial x}\right)+\frac{\partial}{\partial y}\left(k \frac{\partial T}{\partial y}\right)+W=0
$$

where, $k(\mathrm{~W} / \mathrm{m} \cdot \mathrm{K})$ is the heat transfer coefficient.

Table 2 shows the parameters used in the calculations. The resistance of the $\mathrm{BD}, R$, is calculated using the experimental results. The heat transfer coefficient [13-15] $k$ for the filler in the junction box is assumed to be the typical value for silicone resin. The cross-sectional area for heat flux is set to the surface area of the BD box. 
Table 2 Important parameters for calculation.

\begin{tabular}{ll}
\hline Area & $34 \mathrm{~mm} \times 23 \mathrm{~mm}$ \\
\hline Thickness $(\mathrm{mm})$ & \\
\hline Module & 46 \\
Filler & 3.5 \\
Cover glass & 3 \\
EVA & 43 \\
\hline Heat transfer coefficient $(\mathrm{W} / \mathrm{m} \cdot \mathrm{K})$ & \\
\hline Filler & 0.2 \\
Cover glass & 1.03 \\
EVA & 0.3 \\
BD box & 100 \\
Number of BDs & 2 \\
Resistance of BD $(\Omega)$ & 0.072 (two BDs) \\
\hline
\end{tabular}

Convective heat transfer was not considered and the lateral surface of the module and the surface of the cover glass were assumed to be at ambient temperature. $\Delta T_{1}$ was calculated at increments of $1 \mathrm{~A}$ from $1 \mathrm{~A}$ to $7 \mathrm{~A}$.

Fig. 11 shows the simulation result of the temperature distribution at $7 \mathrm{~A}$. The $\mathrm{X}$-axis and $\mathrm{Y}$-axis express the width and depth of the junction box, respectively. The temperature at the $\mathrm{BD}$ box $T_{1}$ reaches $110{ }^{\circ} \mathrm{C}$ and decreases drastically around the BD box. Almost the same tendency is observed in the case from 1 to $6 \mathrm{~A}$. The calculated results and measured temperatures are shown in Fig. 12. The experimental results and the results of the calculation show similar tendencies.

Then, an electric current through the $\mathrm{BD}$ is calculated while considering the heat flux in the junction box. The heat flux density $\dot{q}_{v}\left(\mathrm{~W} / \mathrm{m}^{3}\right)$ along the $\mathrm{Y}$-axis is expressed by an equation of heat conduction with internal heat generation:

$$
\dot{q}_{v}=\frac{2 q(y)}{y}
$$

where, $q(y)\left(\mathrm{W} / \mathrm{m}^{2}\right)$ is the heat flux, $y(\mathrm{~m})$ is the thickness of the object. $q(y)$ is expressed using $T_{1}, T_{2}$ and the thickness of the filler $L(\mathrm{~m})$ as follows:

$$
q(y)=\frac{k}{L}\left(T_{1}-T_{2}\right)
$$

Thus, the current through the $\mathrm{BD} I_{C}(\mathrm{~A})$ is derived using Joule's law:

$$
I_{C}=\sqrt{\frac{Q}{R}}=\sqrt{\frac{\dot{q}_{v} A L}{R}}=\sqrt{\frac{2 k\left(T_{1}-T_{2}\right) A}{R y}}
$$

where, $A\left(\mathrm{~m}^{2}\right)$ is the area under consideration. Here, the calculated temperature is used for the temperature on the $\mathrm{BD}$ box $T_{1}$.

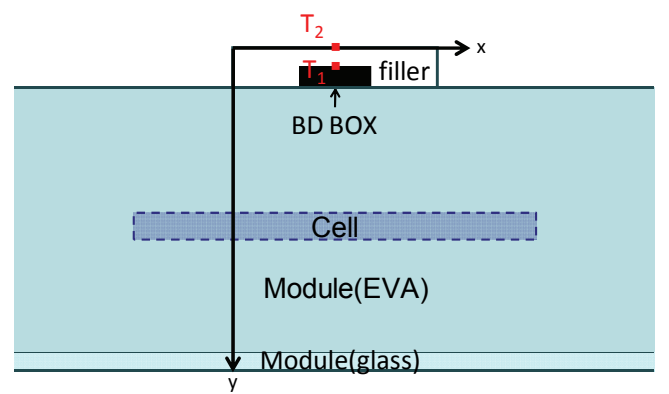

Fig. 10 Schematic diagram of the cross-section of the module.

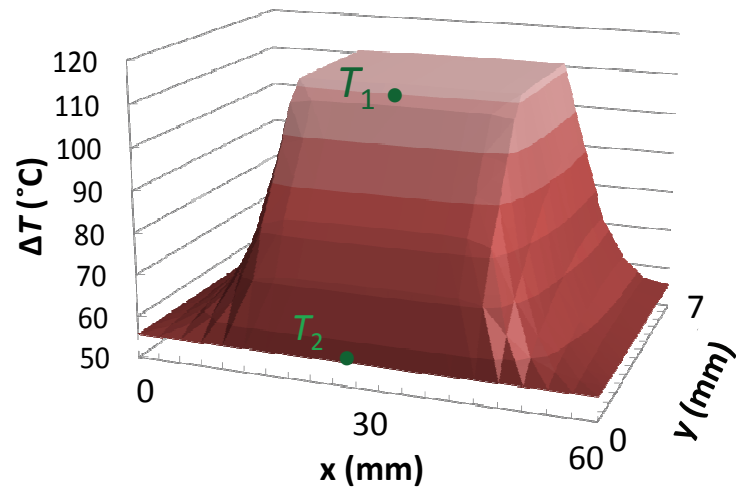

Fig. 11 Simulation result of temperature distribution (7A).

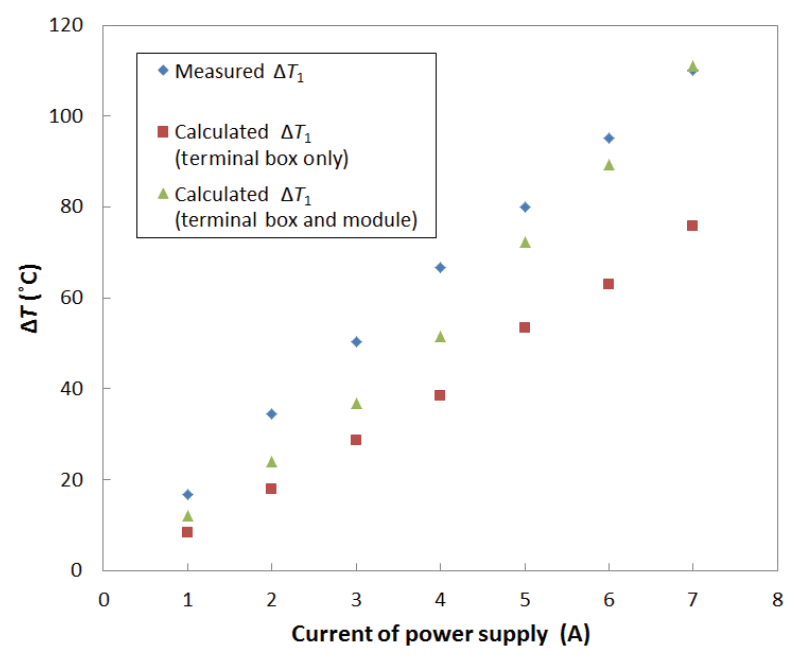

Fig. 12 Calculated results and measured temperature. 


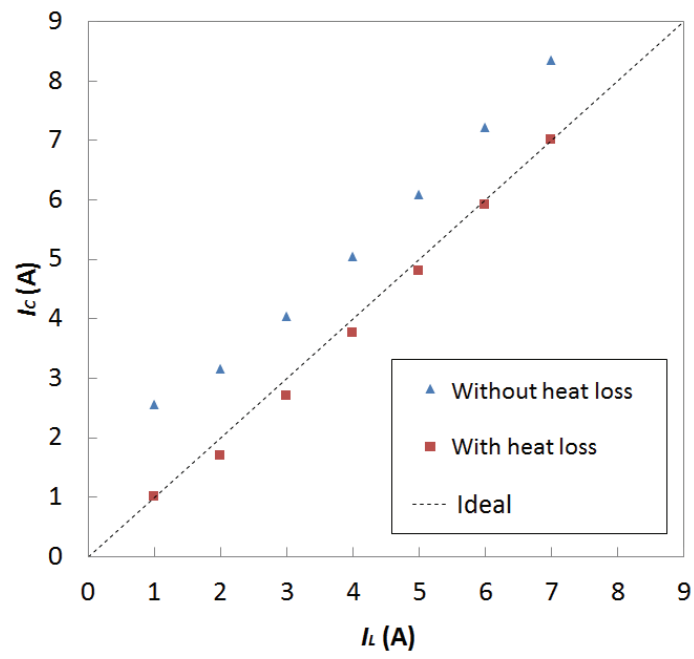

Fig. 13 Relationship between $I_{C}$ and $I_{L}$ with and without heat loss.

From the results of the calculation, the relationship between $I_{C}$ and the applied current from the power supply to BD $I_{L}$ is shown on Fig. 13. The dashed-line on the figure shows the ideal relationsip $\left(I_{C}=I_{L}\right)$. The calculated $I_{C}$ derived from Eq. (5) is plotted as blue triangles. All values show a higher tendency than the ideal line because of the no heat loss consideration. Then, a correction was made to consider heat loss in the module. The heat loss was approximately calculated from the expetrimental results at $1 \mathrm{~A}$ and 7 A. Thus, the equation for $I_{C}$ is arranged with the heat loss $Q_{\text {loss }}$ as follows:

$$
I_{C}=\sqrt{\frac{Q-Q_{\text {loss }}}{R}}=\sqrt{\frac{2 k\left(T_{1}-T_{2}\right) A-Q_{\text {loss }} y}{R y}}
$$

The $I_{C}$ values derived from Eq. (6) are shown on Fig. 13 as red squares. As the results show, the $I_{C}$ values are almost equal to the ideal currents. After all, it was suggested that a current passing through a BD can be estimated easily by measuring the temperature on the junction box.

\section{Conclusions}

The temperature of BD mounted on PV modules was measured and investigated for simple and practical fault detection. Measuring a BD temperature is easier than other conventional fault detection methods. From the results of the rise in BD temperature under dark conditions, the increase in temperature increased linearly with increasing current flow. There is a proportional relationship between heat generated and the increasing temperature of the terminal box. From the results of the surface temperature of the junction box in actual system operation, the rise in temperature of the module which had a failure, was almost equal to the obtained results of a single BD under dark conditions. Thus, it was supposed that the electric current through a $\mathrm{BD}$ in a terminal box can be known by measuring the surface temperature of the terminal box for PV module fault detection. Besides, we tried to evaluate the distribution of temperature of a junction box using heat conduction equations. The evaluated results agreed very well with experimental results considering heat loss in the module.

In conclusion, a current through a BD can be easily estimated by measuring the temperature on the junction box without a system shutdown. Therefore, it is desirable that manufacturers provide a database of parameters for making such estimations in the future.

\section{Conflict of Interests}

The authors declare that there is no conflict of interests regarding the publication of this article.

\section{Acknowledgments}

We wish to thank Dr. Kazuhiko Kato of the National Institute of AIST (Advanced Industrial Science and Technology) for technical support.

\section{References}

[1] IEA PVPS. 2016. "Trends in Photovoltaic Applications." International Energy Agency. Library. Accessed November $\quad 14, \quad 2016$. http://iea-pvps.org/fileadmin/dam/public/report/national/T rends_2016_-_mr.pdf.

[2] Celik, A. N. 2007. "Effect of Different Load Profiles on the Loss-of-Load Probability of Stand-Alone Photovoltaic Systems." Renewable Energy 32 (12): 2096-115. 
[3] Zheng, H., Li, S., Challoo, R., and Proano, J. 2014. "Shading and Bypass Diode Impacts to Energy Extraction of PV Arrays under Different Converter Configurations." Renewable Energy 68 (August): 58-66.

[4] Bouraiou, A., Hamouda, M., Chaker, A., Sadok, M., Mostefaoui, M., and Lachtar, S. 2015. "Modeling and Simulation of Photovoltaic Module and Array Based on One and Two Diode Model Using Matlab/Simulink." Energy Procedia 74 (August): 864-77.

[5] Belhaouas, N., Cheikh, M. S., Malek, A., and Larbes, C. 2013. "Matlab-Simulink of Photovoltaic System Based on a Two-Diode Model Simulator with Shaded Solar Cells." Revue des Energies Renouvelables 16 (1): 65-73.

[6] Zheng, H., Li, S., Haskew, T. A., and Xiao, Y. 2013. "Impact of Uneven Shading and Bypass Diodes on Energy Extraction Characteristics of Solar Photovoltaic Modules and Arrays." International Journal of Sustainable Energy 32 (5): 351-65.

[7] Murtaza, A., Chiaberge, M., Spertino, F., Boero, D., and Giuseppe, M. 2014. “A Maximum Power Point Tracking Technique Based on Bypass Diode Mechanism for PV Arrays under Partial Shading." Energy and Buildings 73 (April): 13-25.

[8] Jung, T. H., Kang, G. H., and Ahn, H. K. 2014. "Optimal Design of PV Module with Bypass Diode to Reduce
Degradation due to Reverse Excess Current." Transactions on Electrical and Electronic Materials 15 (5): 279-83.

[9] Bauwens, P., and Doutreloigne, J. 2014. "Reducing Partial Shading Power Loss with an Integrated Smart Bypass.” Solar Energy 103 (May): 134-42.

[10] Daliento, S., Napoli, F., Guerriero, P., and Alessandro, V. 2016. "A Modified Bypass Circuit for Improved Hot Spot Reliability of Solar Panels Subject to Partial Shading." Solar Energy 134 (September): 211-8.

[11] Kurokawa, K., and Wakamatsu, S. 2014. Guidbook for Design of Solar Photovoltaic Poer Generation System. Ohmsha. (in Japanese).

[12] Deutsche Gesellschaft fuer Sonnenenergie. 2013. Planning and Installing Photovoltaic Systems: A Guide for Installers, Architects and Engineers. Routledge.

[13] Japan Society of Thermophysical Properties. 2000. Thermophysical Properties Handbook. Yokendo. (in Japanese).

[14] Japan Society of Mechanical Engineers. 1993. JSME Data Book: Heat Transfer. Maruzen. (in Japanese).

[15] Sugimoto, E. 2008. Solar Photovoltaic System Construction Material. Electrical and Electronic materials Society, Kogyo Chosakai Publishing. (in Japanese). 